\title{
Risk of Adverse Health Outcomes with Increasing Duration and Regularity of Opioid Therapy
}

\author{
Leonard J. Paulozzi, MD, Kun Zhang, PhD, Christopher M. Jones, PharmD, \\ and Karin A. Mack, PhD
}

Purpose: The purpose of this study was to examine trends in frequency and daily dosage of opioid use and related adverse health outcomes in a commercially insured population.

Methods: We examined medical claims from the Truven Health MarketScan commercial claims database for 789,457 continuously enrolled patients ages 18 to 64 years to whom opioids were dispensed during the first half of 2008 . We tracked them every 6 months until either opioid use was discontinued or the end of 2010. We compared outcomes among all opioid users with those for patients who used opioids with only limited interruptions during the index period, referred to as "daily users." We contrasted the experience of daily users, other users, and nonusers for various outcomes.

Results: Of all claimants, $10.7 \%$ had at least one opioid prescription during the first 6 months of 2008. Of these, $39.9 \%$ continued through a second 6 -month period, and $18.0 \%$ continued through the end of 2010. Only $9.0 \%$ of all users qualified as daily users, but $87.1 \%$ of them continued some use of opioids through the end of 2010 . Only $43.8 \%$ of all users who continued use through 2010 initially qualified as daily users. Among all users who continued use through 2010, days of use and daily dosage increased with duration of use. Among daily users, only dosage increased, rising from 101 to 114 morphine milligram equivalents/day over the 3 years. The prevalence of benzodiazepine use was greater for daily than all users, exceeding $\mathbf{4 0} \%$ among daily users who continued opioid use for 3 years. Drug abuse and overdose rates increased with longer use. Daily users accounted for $25.0 \%$, other users for $\mathbf{4 3 . 6 \%}$, and nonusers for $31.4 \%$ of opioid analgesic overdoses.

Conclusions: Adverse health outcomes can increase with accumulating opioid use and increasing dosage. Existing guidelines developed by specialty societies for managing patients using opioids daily or nearly daily do not address the larger number of patients who use opioids intermittently over periods of years. Practitioners should consider applying such guidelines to patients who use opioids less frequently. (J Am Board Fam Med 2014;27:329-338.)

Keywords: Analgesics, Drug Abuse, Pain Management, Poisoning

The use of opioid analgesics in the United States has expanded steadily for 2 decades. ${ }^{1,2}$ As of 2011, 1 of every 17 prescriptions in the United States was writ-

This article was externally peer reviewed.

Submitted 6 November 2013; revised 6 February 2014; accepted 10 February 2014.

From the Division of Unintentional Injury Prevention, National Center for Injury Prevention and Control, Centers for Disease Control and Prevention, Atlanta, GA.

Funding: All work for this manuscript was funded by the Centers for Disease Control and Prevention.

Conflict of interest: none declared.

Disclaimer: The findings and conclusions in this manuscript are those of the author(s) and do not necessarily represent the views of the Centers for Disease Control and Prevention.

Corresponding author: Leonard J. Paulozzi, MD, El Paso Quarantine Station, 601 Sunland Park Drive, Suite 200, El Paso, TX 79912 (E-mail: lbp4@cdc.gov). ten for an opioid, with 238 million opioid prescriptions dispensed that year. ${ }^{3}$ Most of those prescriptions were for hydrocodone combination products and were issued for courses of $\leq 3$ weeks. ${ }^{4}$ Each year, roughly 1 in 5 adults treat their pain, whether acute or chronic, with an opioid, ${ }^{5-7}$ and more of those adults are treated by family medicine specialists or general practitioners than any other specialty. ${ }^{4}$ Since at least 1999, increasing use of opioids has been accompanied by dramatic increases in the rates of abuse, overdose, and substance abuse treatment admissions involving this class of drugs. ${ }^{8}$

Most studies of opioid usage, however, have concentrated on the subpopulation of patients with chronic conditions such as back pain, arthritis, and headache. For example, the Consortium to Study 
Opioid Risks and Trends (CONSORT) study of managed care populations in Washington and California focused on the $4 \%$ to $5 \%$ of adults who used opioids "long-term" for chronic pain. ${ }^{6}$ The Trends and Risks of Opioid Use for Pain (TROUP) study included the $9 \%$ of commercial insurance plan members and the $22 \%$ of the Arkansas Medicaid populations with certain chronic pain conditions that had been treated with opioids. ${ }^{9}$ Publications based on the Health Care for Communities survey also were limited to "regular" users of opioids. ${ }^{10}$ Even the most cited guidelines for opioid use ${ }^{11}$ address chronic opioid therapy, defined as daily or near daily use.

This focus on certain subpopulations neglects the majority of opioid users. The CONSORT study, for example, found that roughly $5 \%$ of episodes of opioid use were long-term. ${ }^{12}$ A study of insurance claims of patients 18 to 64 years old who were treated with opioids in 2009 found that $28 \%$ had acute pain conditions such as trauma, $14 \%$ had chronic noncancer pain conditions, and $24 \%$ had a combination of acute and chronic pain. ${ }^{13}$ The remainder (44\%) had other and unspecified conditions.

In addition, while many patients in the United States have now used opioids for years, few studies to date have taken a longitudinal approach. ${ }^{14}$ Most of what is known about extended treatment with opioids and related adverse health events comes from clinical trials less than a year in duration ${ }^{15,16}$ and open-label extensions of such trials. ${ }^{17}$ As a result, we know that usage carries a risk of overdose $^{18}$ but not how that risk changes over time in actual practice. We know that risk increases with daily dosage ${ }^{18}$ but not how dosage changes over time for either the group defined as receiving "long-term opioid therapy"12 or others using opioids more irregularly. From a population perspective, we also do not know how much of the epidemic of opioid analgesic overdoses should be attributed to daily use versus other use. To begin broadening our understanding of the larger population of opioid users, we conducted a retrospective cohort study of a large, commercially insured patient population prescribed opioids for any reason, following them for 3 years to see how their usage and risk of adverse health outcomes changed. We compared them to a better-described subgroup of patients who meet a definition of daily opioid use to determine how representative daily users are of all opioid users. Finally, we compared daily users and other users with people without opioid prescriptions. Our findings have implications for both clinical practice guidelines and public health policy.

\section{Methods}

\section{Data Source}

We analyzed the 2008 to 2010 Truven Health MarketScan Commercial Claims and Encounters databases, which include people with employersponsored insurance as their primary coverage. The MarketScan databases contain standardized, enrollee-level claim information across inpatient, outpatient, and prescription drug services from the records of approximately 150 self-insured employers and 20 large commercial health insurance plans. Truven Health weights the data to be representative of the roughly 175 million people with employer-sponsored insurance in the United States. Outpatient service claims provide patient age and sex, date of visit, and up to 4 fields for diagnoses assigned to the visit. Pharmaceutical claims include the drug name, date dispensed, therapeutic class, national drug code, quantity dispensed, and days of supply. No patient identifiers are available, and this study did not require human subjects review. We have described the methods in detail elsewhere. ${ }^{13}$

\section{Study Population}

\section{Opioid Users}

We identified 7,405,800 patients, 18 to 64 years old, without a cancer diagnosis who were enrolled and had drug coverage every month during 2008 to 2010. Cancer diagnosis was based on International Classification of Diseases, 9th Revision, Clinical Modification (ICD-9-CM) codes (338.3; 140 $172.9 ; 174-215.9 ; 217-229.10$; or 235-239.9). From this group, we identified 823,310 patients who had at least one opioid prescription dispensed during January to June 2008. We then excluded 33,853 enrollees (4.1\%) because their opioid prescription records had missing or improbable data, for example, $>180$ days of supply or quantity of $>1,000$ pills. This left 789,457 people as the initial study cohort, or $10.7 \%$ of all claimants. We divided the years 2008 to 2010 into 6, 6-month time periods and assessed enrollees during each time period until discontinuation. Discontinuation was defined as not having any opioid prescription during a January through June or July through December time 
period, similar to the definition used by Martin et al. ${ }^{14}$ We stratified the study population by their duration of use: user group 1, which used only during the first 6 months; user group 2, which used during the first 2 time periods before discontinuing; through to user group 6, which used opioids in all 6 time periods. By the final time period, the initial study cohort had been reduced to 141,799 (Figure 1). Opioid prescriptions before January 2008 were not considered, so these were not necessarily new episodes of opioid analgesic use.

\section{Daily Opioid Users}

We identified a subpopulation of 71,253 "daily" opioid users within the initial cohort using the definition of "regular" users from the TROUP study. ${ }^{14}$ Daily users were defined by days of opioid use during January-June, 2008, the index time period in this study. During this time period, daily users had to have no more than 31 days between (1) January 1 and the first day of their first opioid prescription, (2) the end date and start date of any 2 consecutive opioid prescriptions during the time period, and (3) the last day of the last opioid prescription and June 30. Daily users comprised 9.0\% of the initial study cohort (Figure 1).

\section{Nonusers}

We defined nonusers as people without cancer diagnoses who were continuously enrolled during 2008 to 2010 but did not receive an opioid prescription during the index time period. We exam-

Figure 1. Opioid analgesic users by type and duration of use, 2008 to 2010, Truven Health MarketScan.

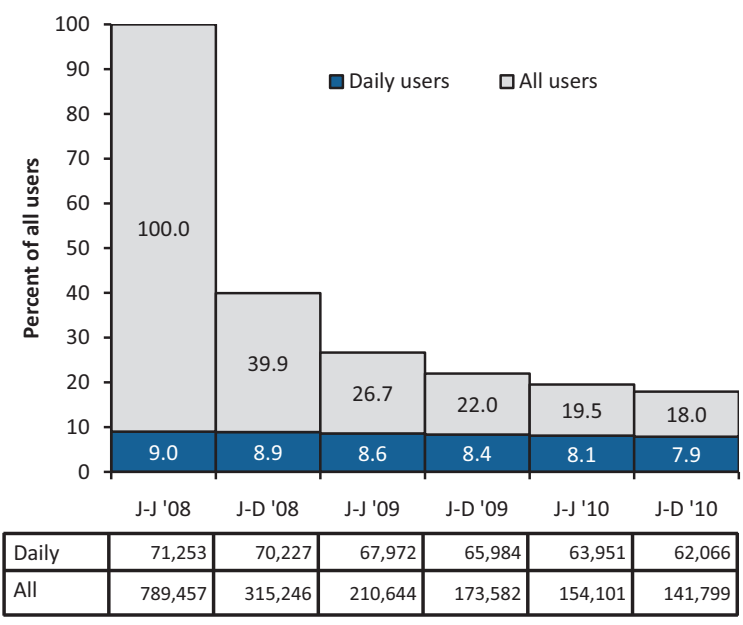

ined their characteristics only during the index period.

\section{Measures of Opioid Use}

Indicators of general opioid use included the mean and median days of use (where one or more opioid prescriptions was active) and mean and median daily dosages for opioids in morphine milligram equivalents (MMEs). Both semisynthetic (eg, hydrocodone) and synthetic opioids (eg, tramadol) were included. Buprenorphine was not included because of its predominant use as a substance-abuse treatment. A complete list is available upon request. Morphine equivalent conversion factors used have been previously described. ${ }^{19}$ Opioid usage indicators were calculated by period until a patient discontinued opioid use. Patients might have resumed opioid use after discontinuation, but they were not included in subsequent time periods.

\section{Outcome Indicators}

We examined use of opioids with benzodiazepines, drug abuse, and drug overdose as significant adverse health outcomes among opioid users. Use of a benzodiazepine was defined as having one or more benzodiazepine prescriptions during a time period, irrespective of whether that use overlapped with use of an opioid. Because we were primarily interested in diagnoses related to the use of opioids and other prescription drugs, we excluded outcomes related to illicit drugs. Therefore, drug abuse was defined as one or more diagnoses of drug dependence or abuse not specific to illicit drugs (ICD9-CM codes 304.0, 304.1, 304.6-304.9, 305.4, 305.5, 305.8). Similarly, we used the outpatient service claims to calculate rates of drug overdose per 1000 patients from pharmaceuticals that are often used nonmedically, primarily central nervous system and psychotherapeutic drugs (ICD9-CM codes 965.00, 965.02, 965.09, 965.8, 965.9, 967, 969 except for 969.6, 975.2, 975.3, 977.8, and 977.9). Most of the drugs in this set of codes are classified as controlled substances. Use of this set of drugs rather than the complete range of drug overdose codes excluded overdoses attributed to illicit drugs as well as to prescription drugs not prone to abuse, such as insulin and anticoagulants, which were common among the claims. We also calculated rates of the subset of overdoses specifically attributed to opioid analgesics (ICD9-CM codes 965.00, 965.02, 965.09, E850.1, and E850.2). 


\section{Analysis}

Analysis of opioid use and associated outcomes was primarily descriptive. Outcome rates per time period were calculated. Multiple outcomes of the same type noted within one time period, for example, multiple overdoses, were counted only once per time period. We calculated rate ratios and $95 \%$ confidence limits only for overdose rates during the first time period without opioid use in relation to the last time period of opioid use. We calculated the proportions of patients with adverse outcomes that represented daily users, other users, and nonusers.

\section{Results}

Opioid users were $57.5 \%$ female; roughly one quarter of them fell into each of the 18- to 34-, 35to 44-, 45- to 54-, and 55- to 64-year-old age groups. Daily opioid users also were more likely to be female $(57.4 \%)$ and were older: $8.1 \%$ were 18 to 34 years old, $20.6 \%$ were 35 to 44 years old, $42.1 \%$ were 45 to 54 years old, $29.1 \%$ were 55 to 64 years old.

\section{Opioid Use}

Among those using opioids during the first time period, $39.9 \%$ also used opioids during the second time period (Figure 1). Among the 26.7\% who used opioids for the first 18 months, roughly two-thirds (18.0\%) used opioids for the remaining 18 months. Few daily users discontinued use over the 3 years. Nonetheless, by the final time period, daily users still represented fewer than half $(7.9 \%)$ of all users who had continued use for the full 3 years $(19.0 \%)$.

The frequency and dosage of opioid use varied with the type of user (Table 1). Among "all users," those with longer durations of use used opioids for more days during the first time period. Among user groups 1 to 5 , the number of days of use and the mean ( $\sim 50$ MMEs) and median daily opioid dosages ( $\sim 35$ MMEs) did not increase with more time periods of use. In contrast, in user group 6, mean days of use increased 18\% (98-116 days) and mean daily dosage increased 11\% (72-80 MMEs) from the first to the last time period.

By comparison, the subset of daily users had more days of use and higher daily opioid dosage than the group of all users. Daily users in user groups 1 to 5 tapered the frequency of their use of opioids after the index time period; for example, group 5 dropped from 148 days at the outset to 115 days 18 months later. They did not, however, taper their daily dosage: group 5 began at a mean of 83 MMEs and was at 81 MMEs 18 months later. For daily users in user group 6, mean days of use did not increase, but mean daily dosage increased 13\% (101-114 MMEs).

\section{Outcome Indicators}

Among all users (Figure 2), the percentage prescribed a benzodiazepine during a time period of opioid use was higher for those who used opioids for longer periods of time before discontinuing (Figure 2a). Benzodiazepine use, averaged over all time periods of opioid use, ranged from $9.9 \%$ in group 1 to $35.7 \%$ in group 6; it rose from $33.5 \%$ to $37.5 \%$ from time period 1 to 6 among those who used opioids for all 6 time periods. The drug abuse rate increased steadily as long as usage continued for all user groups using for more than one time period and dropped during the time period when usage stopped (Figure 2b). The rate of drug overdose was greater among those using opioids for longer periods of time and generally increased over time (Figure 2c). Rates were consistently higher for those who used opioids for $\geq 2$ years than for people who discontinued use before that milestone. The consistent decline in drug overdose rates when usage stopped, ranging from $33 \%$ to $85 \%$, was statistically significant for all groups. Opioid overdose rates were much lower than drug overdose rates (Figure 2d) and were variable over time, but they were higher among those using opioids for longer time periods.

Daily users (Figure 3), by comparison, were more likely to be prescribed benzodiazepines than all users, and benzodiazepine use was greatest for those continuing opioid use the longest (Figure 3a). Their drug abuse rates (Figure 3b) also increased over time and were generally higher than all users but showed different rankings among user groups: daily users who used for all 6 time periods had the next-to-lowest abuse rates, whereas people using for 5 time periods and then stopping use had the highest abuse rates. Overdose rates, specifically for both drugs and opioids, were higher among daily users than all users (Figure 3c, d), but again the group that did not discontinue did not have higher rates. The declines in overdose rates with opioid discontinuation were all statistically significant. 


\begin{tabular}{|c|c|c|c|c|c|c|c|c|c|c|c|c|c|}
\hline \multirow{3}{*}{$\begin{array}{l}\text { Characteristics } \\
\text { by User Group }\end{array}$} & \multicolumn{12}{|c|}{ Time Period of Opioid Use } & \multirow{3}{*}{$\begin{array}{l}\text { Mean } \\
\text { Use }\end{array}$} \\
\hline & \multicolumn{2}{|c|}{ Jan-June 2008} & \multicolumn{2}{|c|}{ July-Dec 2008} & \multicolumn{2}{|c|}{ Jan-June 2009} & \multicolumn{2}{|c|}{ July-Dec 2009} & \multicolumn{2}{|c|}{ Jan-June 2010} & \multicolumn{2}{|c|}{ July-Dec 2010} & \\
\hline & Mean & Median & Mean & Median & Mean & Median & Mean & Median & Mean & Median & Mean & Median & \\
\hline \multicolumn{14}{|l|}{ All users* } \\
\hline \multicolumn{14}{|l|}{ Days of use } \\
\hline Group 1 & 8 & 5 & & & & & & & & & & & 8 \\
\hline Group 2 & 16 & 6 & 14 & 6 & & & & & & & & & 15 \\
\hline Group 3 & 26 & 10 & 28 & 10 & 21 & 9 & & & & & & & 25 \\
\hline Group 4 & 40 & 16 & 43 & 20 & 42 & 20 & 33 & 15 & & & & & 40 \\
\hline Group 5 & 50 & 25 & 55 & 30 & 55 & 30 & 53 & 30 & 37 & 20 & & & 50 \\
\hline Group 6 & 98 & 92 & 107 & 114 & 110 & 120 & 115 & 128 & 115 & 130 & 116 & 132 & 110 \\
\hline \multicolumn{14}{|l|}{$\begin{array}{c}\text { Daily dosage } \\
\text { (MME) }\end{array}$} \\
\hline Group 1 & 52 & 37.5 & & & & & & & & & & & 52 \\
\hline Group 2 & 50 & 37.5 & 50 & 38 & & & & & & & & & 50 \\
\hline Group 3 & 50 & 36 & 50 & 36 & 48 & 37 & & & & & & & 49 \\
\hline Group 4 & 50 & 35 & 50 & 35 & 50 & 35 & 50 & 35 & & & & & 50 \\
\hline Group 5 & 53 & 35 & 52 & 35 & 52 & 34 & 52 & 34 & 50 & 33 & & & 52 \\
\hline Group 6 & 72 & 38 & 74 & 39 & 75 & 40 & 77 & 40 & 79 & 40 & 80 & 40 & 76 \\
\hline \multicolumn{14}{|l|}{ Daily users $^{\dagger}$} \\
\hline \multicolumn{14}{|l|}{ Days of use } \\
\hline Group 1 & 134 & 137 & & & & & & & & & & & 134 \\
\hline Group 2 & 138 & 145 & 76 & 60 & & & & & & & & & 107 \\
\hline Group 3 & 142 & 150 & 116 & 120 & 66 & 57 & & & & & & & 108 \\
\hline Group 4 & 147 & 153 & 130 & 146 & 112 & 120 & 76 & 60 & & & & & 116 \\
\hline Group 5 & 148 & 160 & 137 & 150 & 125 & 144 & 115 & 127 & 70 & 60 & & & 119 \\
\hline Group 6 & 157 & 167 & 154 & 168 & 151 & 166 & 154 & 169 & 150 & 166 & 150 & 168 & 153 \\
\hline \multicolumn{14}{|l|}{$\begin{array}{c}\text { Daily dosage } \\
\text { (MME) }\end{array}$} \\
\hline Group 1 & 54 & 34 & & & & & & & & & & & 54 \\
\hline Group 2 & 70 & 39 & 66 & 38 & & & & & & & & & 68 \\
\hline Group 3 & 69 & 37 & 69 & 37 & 61 & 36 & & & & & & & 66 \\
\hline Group 4 & 74 & 40 & 75 & 40 & 75 & 40 & 71 & 39 & & & & & 74 \\
\hline Group 5 & 83 & 41 & 80 & 41 & 83 & 40 & 81 & 40 & 72 & 38 & & & 80 \\
\hline Group 6 & 101 & 46 & 105 & 47 & 108 & 48 & 111 & 50 & 113 & 51 & 114 & 51 & 109 \\
\hline
\end{tabular}

Data from Truven Health MarketScan.

*Among all users, group 1 included 474,211 patients; group 2, 104,602 patients; group 3, 37,062 patients; group 4, 19,481 patients; group 5, 12,302 patients; and group 6, 141,799 patients. Total number of patients was 789,457.

${ }^{+}$Among daily users, group 1 included 1,026 patients; group 2, 2,255 patients; group 3, 1,988 patients; group 4, 2,033 patients; group 5, 1,885 patients; and group 6, 62,066 patients. Total number of patients was 71,253.

MME, morphine milligram equivalent.

\section{Comparisons of User Groups}

Of the 7405,800 people continuously enrolled during 2008 to 2010 without cancer diagnoses, $89.3 \%$ did not have an opioid prescription during the first half of 2008 (Figure 4). During the first time period, these nonusers had a prevalence of benzodiazepine use of $4.1 \%$, a rate of drug abuse diagnosis of 0.3 per 1000 people, a drug overdose rate of 0.2 per 1000 people, and an opioid overdose rate of 0.01 per 1000 people. Daily opioid users accounted for $1.0 \%$ and all other opioid users accounted for $9.7 \%$ of the 7.4 million people. Daily users accounted for $32.4 \%$ of drug abuse diagnoses, $11.1 \%$ of drug overdoses, and $25.0 \%$ of opioid overdoses during that 6-month period. They also accounted for $50.5 \%$ of all days of opioid use in the population (data not shown). Other users accounted for $49.5 \%$ of days of opioid use and $43.6 \%$ of opioid overdoses during that 6-month period. Calculated on a population basis over 6 months, daily users had an 
Figure 2. Selected outcomes among opioid analgesic user groups by time period, 2008 to 2010, Truven Health MarketScan. A: Percentage of users prescribed a benzodiazepine. B: Drug abuse rate per 1000 people. C: Drug overdose rate per 1000 people. D: Opioid analgesic overdose rate per 1000 people. Numbers 1-6 refer to user groups. Circles indicate time periods without opioid use. J-J, January through June; J-D, July through December.

A Percent prescribed a benzodiazepine

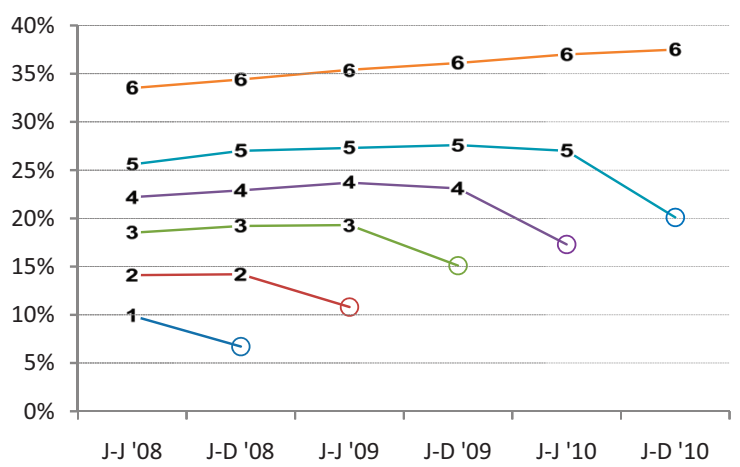

B Drug abuse rate per 1,000 people

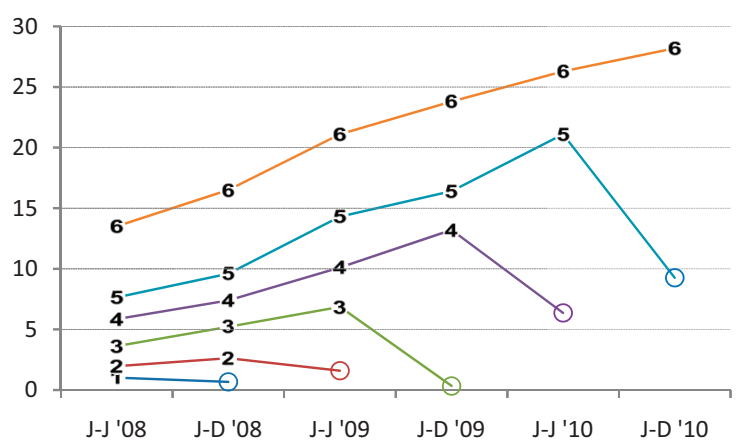

opioid overdose rate of 0.7 per 1000 people, whereas other users had a rate of 0.1 per 1000 people. When calculated based on overdoses per days of use, however, daily users had an opioid overdose rate of 0.4 per 100,000 days of use, whereas other users had a rate of 0.8 per 100,000 days of use (data not shown). Nonusers accounted for almost a third of all opioid overdoses.

\section{Discussion}

We found that use of opioid analgesics among this adult, commercially insured population was common, although most use did not continue use beyond the initial 6-month observation period and lasted for $<10$ days. The rates of benzodiazepine use, drug abuse, and drug overdose increased with duration of opioid use. Daily users, who accounted for only a small fraction of all users, showed trends toward more adverse health outcomes with longer usage.
C Drug overdose rate per 1,000 people

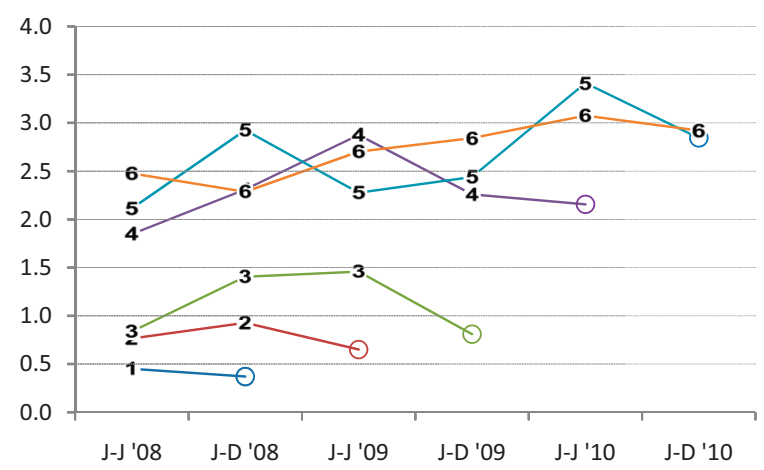

Opioid analgesic overdose rate per 1,000 people

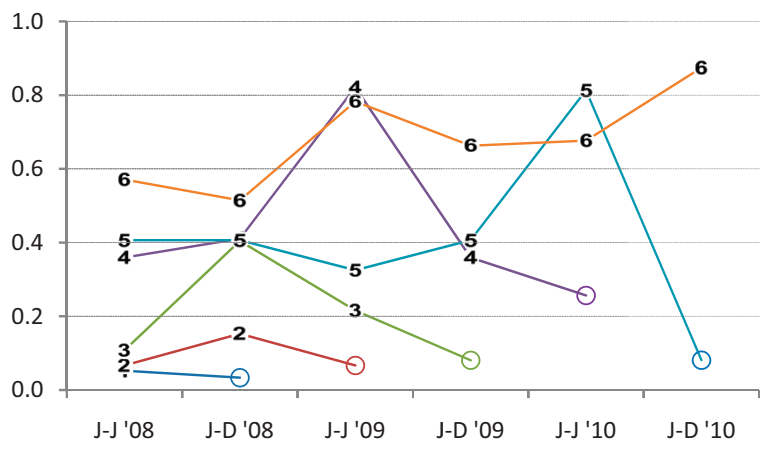

A $10 \%$ prevalence of use of any opioid during a 6-month time period might be roughly half of the annual prevalence rates calculated over 1 year in other studies. One pharmacy benefit manager reported that $18.4 \%$ of people $\geq 18$ years old with commercial insurance had at least one opioid prescription in $1999 .{ }^{5}$ Other studies of health plan data have reported similar annual percentages during 1997 to $2005 .^{6}$

Research has established the high probability of continuing use among daily opioid users. ${ }^{12,14}$ The results of this study indicate that the probability of continued use increases with the duration of use even within the all users group. People taking high daily dosages and who have a history of substance abuse, or those using sedatives, are more likely to continue usage. ${ }^{14}$

Daily dosage in the all users population lacks an appropriate comparison population because other studies have typically been restricted to selected populations with chronic pain conditions, ${ }^{9}$ patients 
Figure 3. Selected outcomes among daily opioid analgesic user groups by time period, 2008 to 2010, Truven Health MarketScan. A: Percentage of users prescribed a benzodiazepine. B: Drug abuse rate per 1000 people. C: Drug overdose rate per 1000 people. D: Opioid analgesic overdose rate per 1000 people. Numbers 1-6 refer to user groups. Circles indicate time periods without opioid use. J-J, January through June; J-D, July through December.

A Percent prescribed a benzodiazepine

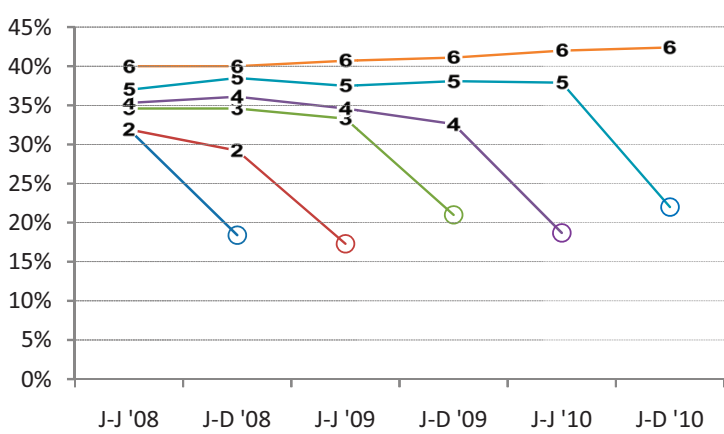

B Drug abuse rate per 1,000 people

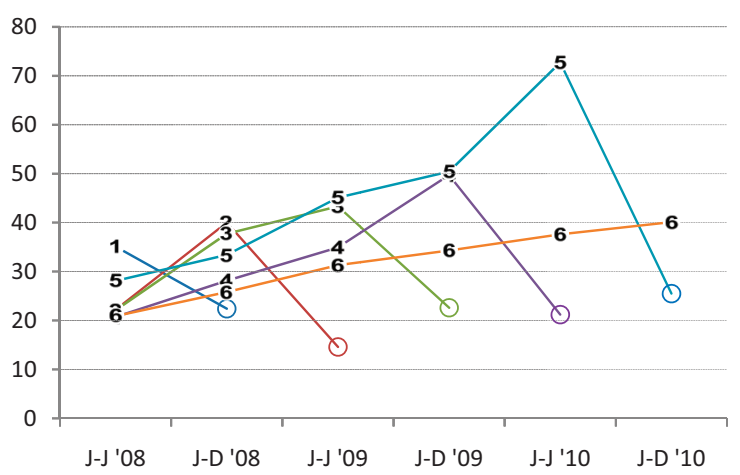

with "long-term" use, or both. ${ }^{20}$ However, even the daily dosages prescribed for patients with an average of $<10$ days of use in the first time period (mean, 52 MMEs; median, 38 MMEs) approximated the dosages prescribed for populations with chronic pain ${ }^{9}$ and long-term use ${ }^{20}$ during 2000 to 2005. On the other hand, the population of daily

Figure 4. Distributions of health outcomes by type of use of opioid analgesics, January through June 2008, Truven Health MarketScan.

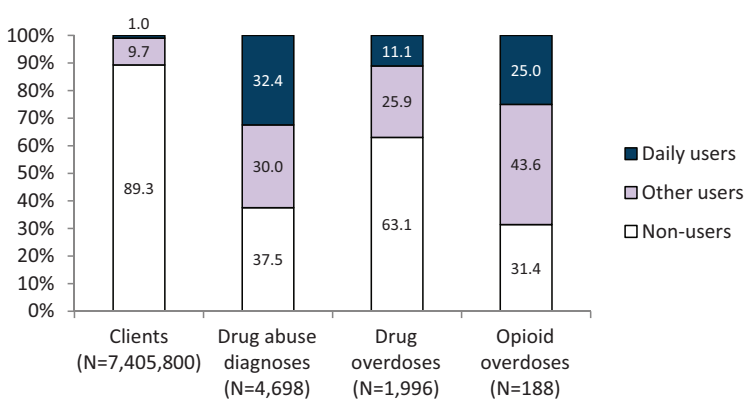

C Drug overdose rate per 1,000 people

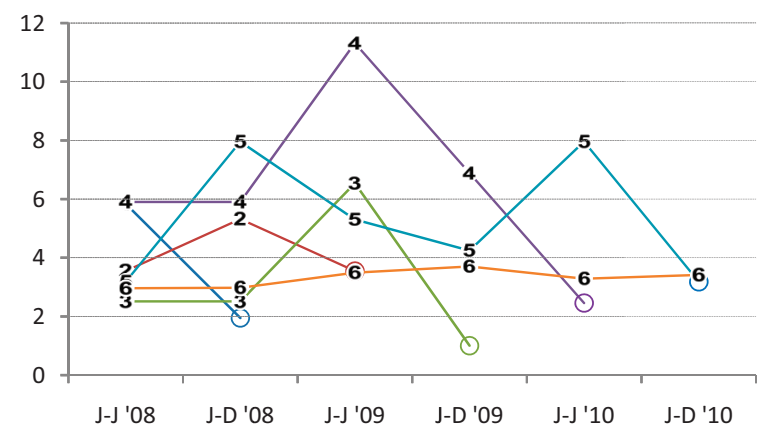

D Opioid analgesic overdose rate per 1,000 people

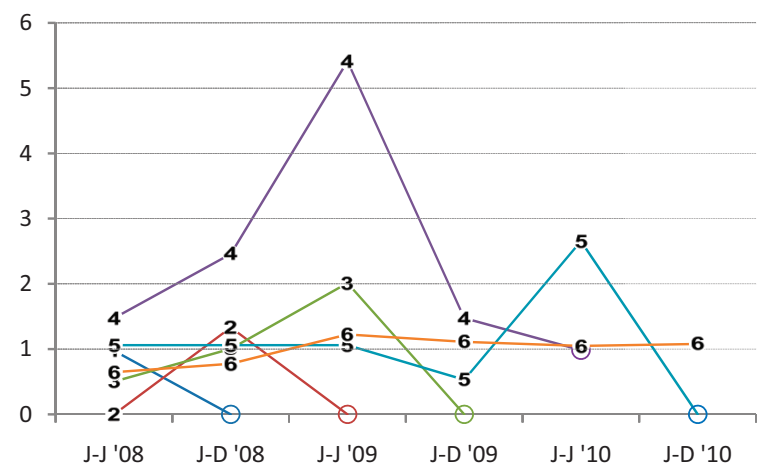

users in this study had substantially higher daily dosages than comparable populations of long-term users in other studies, with means from 54 to 114 MMEs and medians from 34 to 51 MMEs. This might represent differences between this commercial population and health maintenance organization populations in other studies or a secular trend toward higher dosages since $2005 .^{2}$ Some studies have reported dosages in this higher range after $2005 .^{21-23}$

Other studies have reported increases over time in unit dosage strength, ${ }^{24}$ total MMEs per prescription, ${ }^{25}$ or daily dosage ${ }^{17,21-23,26,27}$ in smaller patient cohorts such as workers' compensation claimants. The increase in daily dosage has been concentrated in the first 3 months of therapy. ${ }^{17,26}$ However, most of the daily users in this study who did not discontinue use probably initiated use before the first time period, so their observed increases likely came after the first 3 months of therapy. The observed increase might be 
due to disease progression, physiologic tolerance, or increasing rates of drug abuse. ${ }^{21}$

The prevalence of benzodiazepine usage in the population not using opioids $(4.1 \%)$ was a fraction of that of any of the opioid user groups, even in the 6 months after their opioid use ceased, perhaps because people using opioids are more likely to have mental health disorders. ${ }^{28-32}$ People using opioids at a higher dosage or for longer periods of time are especially likely to use sedatives. ${ }^{33,34}$ Both the high prevalence of benzodiazepine use and its steady increase with longer duration of use among both all and daily users should raise concern given recommendations to avoid combining drug classes associated with respiratory depression. ${ }^{11,35}$ Available data cannot explain why benzodiazepine use dropped when opioid use ceased. Perhaps both drugs were prescribed as treatment for pain that resolved, benzodiazepines were prescribed to treat anxiety related to opioid withdrawal, or both were stopped when patients developed aberrant drug use behaviors.

A history of problem drug use increases the likelihood of opioid use, ${ }^{30}$ but the rising prevalence of a drug abuse diagnosis with longer usage has not been reported previously. The decline in such diagnoses when opioid use ceases might reflect resolution of abuse or simply the absence of such diagnoses on outpatient claims once the patient has stopped seeing prescribers for opioids.

Opioid overdose rates calculated using ICD9-CM codes match those reported elsewhere. ${ }^{18,36}$ For example, one health maintenance population population receiving long-term opioid therapy had an annual rate of overdose of $0.3 \%,{ }^{18}$ whereas the 6 -month rates among daily users in this study, which were doubled to estimate annual rates, ranged from $0.2 \%$ to $0.5 \%$. The increase in overdose rates with longer duration of use might result from more days of opioid use, more overlap with benzodiazepines, ${ }^{18}$ or higher daily opioid dosage. The drop in overdose rates once opioid use ceased suggests that the overdoses during usage were due to the drugs paid for by insurance rather than drugs obtained through other channels, that is, from dealers or by paying cash at pharmacies. The decrease could also represent in part a shift to illicit drugs such as heroin, ${ }^{37}$ overdoses of which are not specifically captured by the overdose definition used here.

The finding that daily users of opioids are more likely to overdose than less heavy users is consistent with previous studies. ${ }^{18,36,38}$ The fact that a substantial fraction of opioid overdoses occur among people who were not prescribed opioids recently (the "nonusers") is consistent with studies of people who die from fatal overdoses of pharmaceuticals, who often have no history of being prescribed the drugs that killed them. ${ }^{39,40}$ Some of the drugs recorded on commercial claims are being diverted to nonpatients.

These results have limitations. Patients might not use drugs dispensed to them. They might also use drugs not prescribed to them or might pay cash rather than filing insurance claims, thus underestimating opioid and benzodiazepine usage. Overdose rates based on ICD9-CM codes are likely underestimates, especially for specific types of poisoning such as opioid poisoning, although they are likely to have a high positive predictive value. ${ }^{41,42}$ Drug abuse rates based on ICD9-CM diagnostic codes are generally a fraction of rates among daily opioid users based on Diagnostic and Statistical Manual of Mental Disorders criteria for opioid use disorder or other definitions. ${ }^{43,44}$ Patients in this study qualified as opioid users during their first and last time periods of use even though they might have used the drugs only during part of the time period. This might account for lower mean days of usage during such time periods, as described in Table 1. Therefore, the risk of overdose during these time periods might not be comparable to risk during other periods. The study could not track patients who died, changed their insurance providers (eg, went on Medicaid), or lost their employer-sponsored insurance during this time interval. Study participants might therefore be at lower risk than the average adult with commercial insurance. Prescription drug monitoring program data would provide a better way to track all opioid users irrespective of changes in their insurance but would not allow a simultaneous assessment of trends in other health outcomes.

\section{Conclusions}

This study demonstrates that patients receiving daily opioid therapy are at the highest risk of opioid overdose but still account for only a quarter of opioid overdoses among an insured population. The remaining group of opioid users accounted for a larger fraction of these overdoses. This suggests that the application of existing clinical guidelines 
for treatment of chronic noncancer pain, ${ }^{11,45}$ while they focus on the group at highest risk, should not necessarily be restricted to daily users with chronic pain conditions. In fact, per day of use, intermittent users might be at greater overdose risk. The increase in risk for adverse health outcomes over time for all opioid users and the decline with cessation of use suggest an additional guideline: clinicians should regularly assess whether it is necessary to continue use of opioids, especially in the absence of decisive benefits. ${ }^{46}$ Clinicians can also mitigate the risk to the nonpatient population from drug diversion by prescribing no more than is needed for pain management.

From a public policy perspective, interventions that focus on the $10 \%$ of the population filling an opioid prescription will address more than half of the people with drug abuse diagnoses or who experiencing opioid overdoses and might indirectly affect the remaining population by preventing drug diversion. In contrast, interventions that address only regular use of opioids for chronic pain conditions might miss a substantial fraction of the at-risk population.

\section{References}

1. Compton WM, Volkow ND. Major increases in opioid analgesics abuse in the United States: concerns and strategies. Drug Alcohol Depend 2006;81: 103-7.

2. Kenan K, Mack K, Paulozzi L. Trends in prescriptions for oxycodone and other commonly used opioids in the United States, 2000-2010. Open Med 2012;6(2):e41.

3. The use of medicines in the United States: review of 2011. Parsippany, NJ: IMS Institute for Healthcare Informatics; 2012. Available from: http://www.imshealth.com/ims/ Global/Content/Insights/IMS\%20Institute\%20for\% 20Healthcare\%20Informatics/IHII_Medicines_in_U.S_ Report_2011.pdf. Accessed March 11, 2014.

4. Volkow N, McLellan T, Cotto J. Characteristics of opioid prescriptions in 2009. JAMA 2011;305:1299301.

5. Roe CM, McNamara AM, Motheral BR. Genderand age-related prescription drug use patterns. Ann Pharmacother 2002;36:30-9.

6. Boudreau D, Von Korff M, Rutter CM, et al. Trends in long-term opioid therapy for chronic non-cancer pain. Pharmacoepidemiol Drug Saf 2009;18:1166-75.

7. Prescription controlled substance dispensing in Oregon: October 1, 2011-March 31, 2012. Schedules II-IV medications dispensed in Oregon, statewide. Portland: Oregon Health Authority; 2012. Available from: http://www.orpdmp.com/orpdmpfiles/PDF_
Files/Reports/Statewide_10.01.11_to_03.31.12.pdf. Accessed March 11, 2014.

8. Centers for Disease Control and Prevention (CDC). Vital signs: overdoses of prescription opioid pain relievers-United States, 1999-2008. MMWR Morb Mortal Wkly Rep 2011;60:1487-92.

9. Sullivan MD, Edlung MJ, Fan M, DeVries A, Braden JB, Martin BC. Trends in use of opioids for non-cancer pain conditions 2000-2005 in commercial and Medicaid insurance plans: the TROUP study. Pain 2008;138:440-9.

10. Hudson T, Edlung M, Steffick D, Tripathi S, Sullivan $M$. Epidemiology of regular prescribed opioid use: results from a national, population-based survey. J Pain Symptom Manage 2008;36:280-8.

11. Chou R, Fanciullo GJ, Fine PG, et al. Clinical guidelines for the use of chronic opioid therapy in chronic noncancer pain. J Pain 2009;10:113-30.

12. VonKorff M, Saunders K, Ray GT, et al. De facto long-term opioid therapy for noncancer pain. Clin J Pain 2008;24:521-7.

13. Liu Y, Logan J, Paulozzi L, Zhang K, Jones C. Potential misuse and inappropriate prescription practices involving opioid analgesics. Am J Manag Care 2013;19:648-58.

14. Martin BC, Fan MY, Edlund MJ, Devries A, Braden JB, Sullivan MD. Long-term chronic opioid therapy discontinuation rates from the TROUP study. J Gen Intern Med 2011;26:1450-7.

15. Kalso E, Edwards JE, Moore RA, McQuay HJ. Opioids in chronic non-cancer pain: systematic review of efficacy and safety. Pain 2004;112:372-80.

16. Noble M, Tregear S, Treadwell J, Shchoelles K. Long-term opioid therapy for chronic noncancer pain: a systematic review and meta-analysis of efficacy and safety. J Pain Symptom Manage 2008;35: 214-28.

17. Portenoy R, Farrar J, Backonja M, et al. Long-term use of controlled-release oxycodone for noncancer pain: results of a 3-year registry study. Clin J Pain 2007;23:287-99.

18. Dunn KM, Saunders KW, Rutter CM, et al. Opioid prescriptions for chronic pain and overdose. Ann Intern Med 2010;152:85-92.

19. Logan J, Liu Y, Paulozzi L, Zhang K, Jones C. Opioid prescribing in emergency departments. Med Care 2013;51:646-53.

20. Campbell CI, Weisner C, LeResche L, et al. Age and gender trends in long-term opioid analgesic use for noncancer pain. Am J Public Health 2010;100:2541-7.

21. Han H, Kass P, Wilsey B, Li C. Age, gender, and earlier opioid requirement associations with the rate of dose escalation in long-term opioid therapy. J Opioid Manage 2013;9:129-38.

22. Cepeda M, Etropolski M, Weinstein R, Fife D, Boston R, Matcho A. Dose patterns in commercially insured subjects chronically exposed to opioids: a large cohort study in the United States. BMC Palliat Care 2010;9:14. 
23. Tao XG, Lavin RA, Yuspeh L, Bernacki EJ. Natural history of opioid dosage escalation post-injury: a cohort study of injured workers in the State of Louisiana. J Occup Environ Med 2012;54:439-44.

24. Gustavsson A, Bjorkman J, Ljungcrantz C, Rhodin A, Rivano-Fischer M, Sjolund K. Pharmaceutical treatment patterns for patients with a diagnosis related to chronic pain initiating a slow-release strong opioid treatment in Sweden. Pain 2012; 153:2325-31.

25. Cifuentes M, Webster B, Genevay S, Pransky G. The course of opioid prescribing for a new episode of disabling low back pain: opioid features and dose escalation. Pain 2010;151:22-9.

26. Schneider J, Kirsh K. Defining clinical issues around tolerance, hyperalgesia, and addiction: a quantitative and qualitative outcome study of long-term opioid dosing in a chronic pain practice. J Opioid Manage 2010;6:385-95.

27. Franklin GM, Rahman EA, Turner JA, Daniell WE, Fulton-Kehoe D. Opioid use for chronic low back pain: a prospective, population-based study among injured workers in Washington state, 2002-2005. Clin J Pain 2009;25:743-51.

28. Braden JB, Sullivan MD, Ray GT, et al. Trends in long-term opioid therapy for noncancer pain among persons with a history of depression. Gen Hosp Psychiatry 2009;31:564-70.

29. Kelly JP, Cook SF, Kaufman DW, Anderson T, Rosenberg L, Mitchell AA. Prevalence and characteristics of opioid use in the US adult population. Pain 2008;138:507-13.

30. Sullivan MD, Edlund M, Steffick D, Unutzer J. Regular use of prescribed opioids: association with common psychiatric disorders. Pain 2005;119:95-103.

31. Sullivan MD, Edlund MJ, Zhang L, Unutzer J, Wells KB. Association between mental health disorders, problem drug use, and regular prescription opioid use. Arch Intern Med 2006;166:2087-93.

32. Seal K, Shi Y, Cohen G, et al. Association of mental health disorders with prescription opioids and highrisk opioid use in US veterans of Iraq and Afghanistan. JAMA 2012;307:940-7.

33. Saunders K, Von Korff M, Campbell CI, BantaGreen C, Sullivan M, Merrill JO. Concurrent use of alcohol and sedatives among persons prescribed chronic opioid therapy: prevalence and risk factors. J Pain 2012;3:266-75.

34. Hermos J, Young M, Gagon D, Fiore L. Characterizations of long-term oxycodone/acetaminophen prescriptions in veteran patients. Arch Int Med 2004;164:2361-6.
35. Washington State Department of Labor and Industries. Guidelines for prescribing opioids to treat pain in injured workers. Olympia, WA: Office of the Medical Director; 2013. Available from: http://www.lni.wa.gov/ claimsins/Files/OMD/MedTreat/FINALOpioid Guideline010713.pdf. Accessed March 11, 2014.

36. Braden JB, Russo J, Fan MY, et al. Emergency department visits among recipients of chronic opioid therapy. Arch Intern Med 2010;170:1425-32.

37. Jones C. Heroin use and heroin use risk behaviors among nonmedical users of prescription opioid pain relievers-United States, 2002-2004 and 2008-2010. Drug Alcohol Depend 2013;132:95-100.

38. Paulozzi LJ, Kilbourne E, Shah N, et al. A history of being prescribed controlled substances and risk of drug overdose death. Pain Med 2012;13:87-95.

39. Hall AJ, Logan JE, Toblin RL, et al. Patterns of abuse among unintentional pharmaceutical overdose fatalities. JAMA 2008;300:2613-20.

40. Ohio Department of Health. Epidemic of prescription drug overdoses in Ohio, 2010. Available from: http:// www.healthy.ohio.gov/vipp/data/ /link.aspx?_id= 16D12C012E474D0BA1670D47C1C71A44\&_z=z. Accessed March 21, 2014.

41. LeMier M, Cummings P, West T. Accuracy of external cause of injury codes reported in Washington State hospital discharge records. Inj Prev 2001;7: 334-8.

42. Blanc P, Jones M, Olson K. Surveillance of poisoning and drug overdose through hospital discharge coding, poison control center reporting, and the Drug Abuse Warning Network. Am J Emerg Med 1993;11:14-9.

43. Sullivan M, Edlund MJ, Fan M, DeVries A, Braden JB, Martin BC. Risks for possible and probable opioid misuse among recipients of chronic opioid therapy in commercial and medicaid insurance plans: the TROUP study. Pain 2010;150:332-9.

44. Boscarino J, Rukstalis M, Hoffman S, et al. Risk factors for drug dependence among out-patients on opioid therapy in a large US health-care system. Addiction 2010;105:1776-82.

45. Washington State Agency Medical Directors' Group. Interagency guideline on opioid dosing for chronic non-cancer pain. Available from: http:// www.agencymeddirectors.wa.gov. Accessed March $11,2014$.

46. Chronic opioid therapy (COT) safety guideline for patients with chronic non-cancer pain. Seattle, WA: Group Health Cooperative; 2012. Available from: http://www.ghc.org/all-sites/guidelines/chronic Opioid.pdf. Accessed March 11, 2014. 